\title{
Comprehensive thickening analysis strategy
}

\author{
P Garrido Centro de Investigación en Minería Sustentable, Chile \\ W Montes Centro de Investigación en Minería Sustentable, Chile \\ K Andrade Centro de Investigación en Minería Sustentable, Chile
}

\begin{abstract}
The main operational issues that arise in the thickening stage are: 1) high variability in feed resulting in failure to achieve the projected treatments due to high levels of torque, poor overflow water quality, and low concentration of solids in discharge; 2) operational inefficiency due to poorly established control loop and lack of knowledge of metallurgical behaviour in thickening and underflow slurry transport; and 3) poor instrumentation and measurement of parameters due to poor or no maintenance, lack of adequate sensors, and poor analysis of the collected information.

The main causes of these problems are undersized equipment, the presence of complex mineralogies, lack or poor quality of measurement of key parameters, and incomplete analysis of relevant operational variables. In such scenarios, the challenge is to identify, in a timely manner, the causes of the limitations in water recovery and operational issues and be able to predict the periods when operational instabilities will arise.

This work presents a comprehensive analysis strategy that considers an automated pilot measurement system, together with an advanced analysis of the experimental and operational data, which allows us to identify, at an early stage, the causes of operational inefficiencies and to propose concrete actions for improvement. The proposed system also considers a modelling stage that predicts the behaviour of the tailings under different mineralogy and treatment scenarios.
\end{abstract}

Keywords: thickening, pilot measurement, simulation

\section{Introduction}

In recent years, Chile has experienced a high water shortage, especially in the northern part of the country where mining is concentrated. Surface water resources are scarce and there is a growing demand for water from industrial users, locals, communities, and the environment.

The consumption of water within copper mining is from two main processes: one is the consumption in hydrometallurgy processes and the other is the consumption in the concentration of minerals. Currently, the global water consumed by the concentration of minerals $(C p)$ is significantly higher than that considered in hydrometallurgical processes, reaching the use of $2.7 \mathrm{Mm}^{3} / \mathrm{yr}$ versus $0.5 \mathrm{Mm}^{3} / \mathrm{yr}$ in 2018 . Consumption by 2029 is expected to increase to $9.3 \mathrm{Mm}^{3} / \mathrm{yr}$ in concentrator plants and $1.6 \mathrm{Mm}^{3} / \mathrm{yr}$ in hydrometallurgical plants (Figure 1, Comisión Chilena del Cobre 2020).

Concentrator plants use three large sources of water: continental water, seawater, and recirculated water. The latter comes mainly from the recovery of water through the thickened tailings and filtering processes. Regarding the water recirculation capacity, we can say that in $2019,74.8 \%$ of the water used in the concentrator plant corresponds to water recovered within the process, percentage that has grown in the last seven years (Figure 2). 


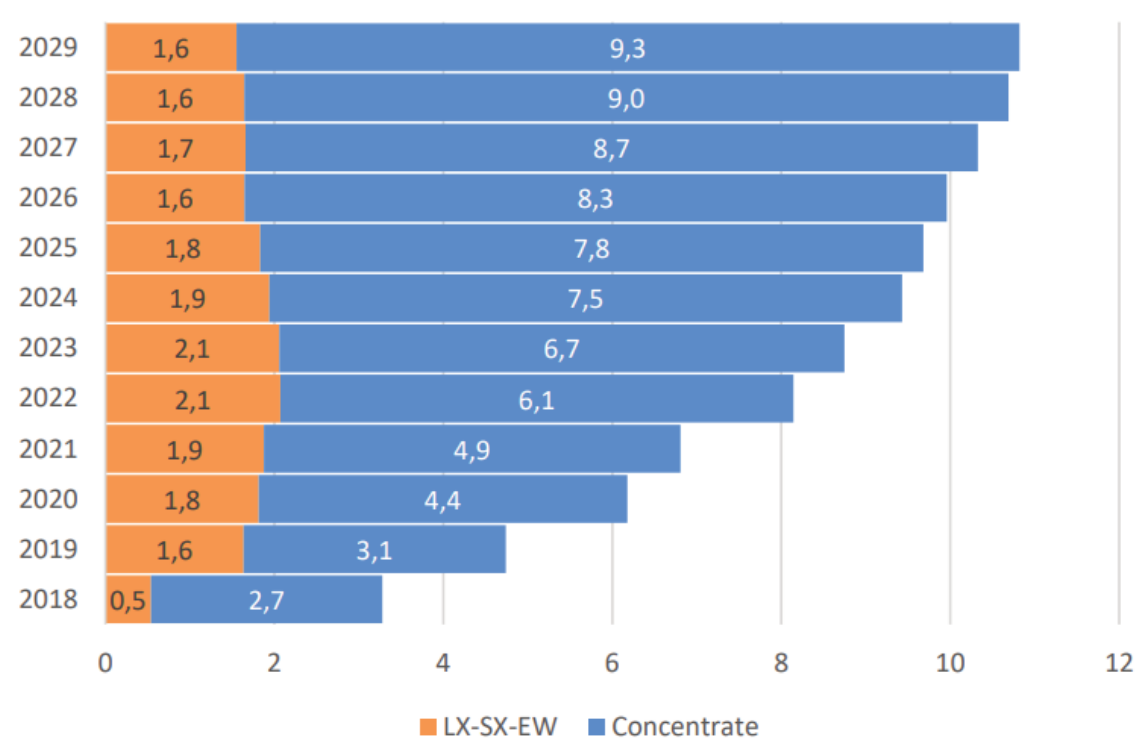

Figure 1 2018-2029 projection of water distribution in concentrator plants and hydrometallurgy plants in the Chilean mining industry (Comisión Chilena del Cobre 2020)
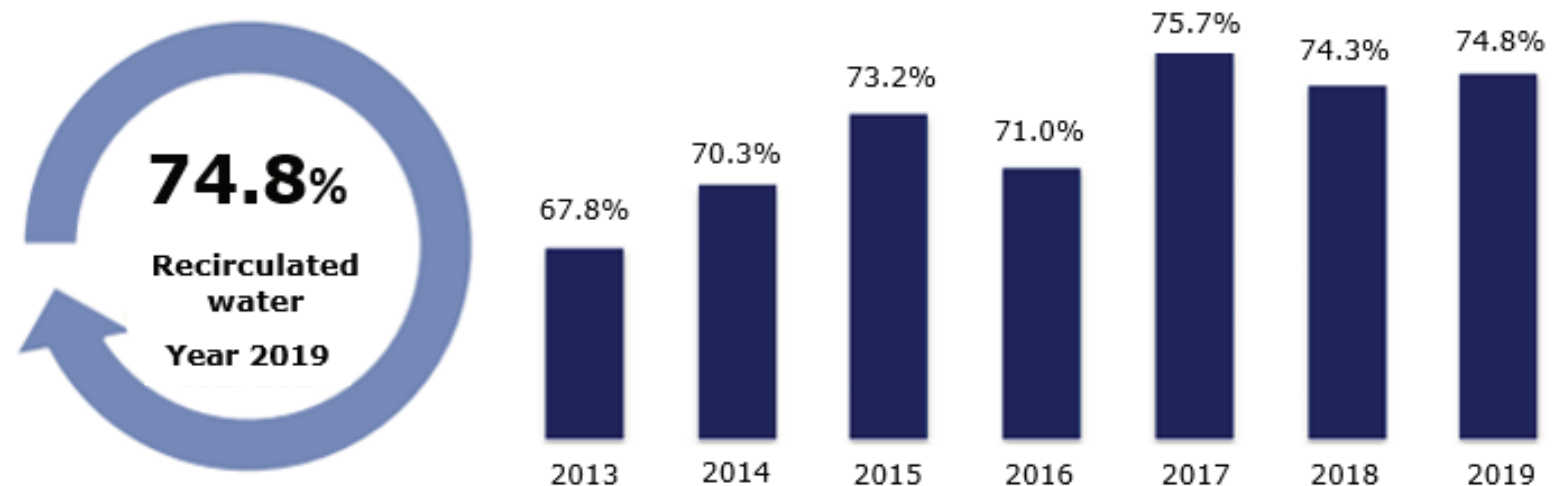

2018

2019

Figure 2 Percentage of recirculated water based on the total water supply in concentrator plants between 2013 and 2019 (Comisión Chilena del Cobre 2018)

In general, the thickening process presents issues in its operation such as bogging of discharge and loss of production due to high torque of the rakes, limited clear water recovery, low clarity of the recovered water, and lower discharge concentrations than those designed. These problems arise from two main points: high variability in the behaviour of the mining slurries that is reflected in their metallurgical characterisation and the lack of critical information to predict the behaviour and not act reactively.

Currently, solutions such as the instrumentation of thickeners have been presented for the monitoring of relevant variables in the process, operational control loops and decision-making by personnel with vast experience in the process, however, these solutions allow evaluating the thickening process at the time it is operating, making decisions based on current variables without taking into account the variability in terms of the mineralogy of the input pulp and the flocculant effectivity. Given this, there is no comprehensive development with established procedures, standardised and regulated, that allow the thickening process to be analysed globally, and in this particular case, there is no methodology that adequately tunes the results obtained with the plant operation.

It has been identified that the way to address these problems should consider a comprehensive and timely diagnosis of the causes and the evaluation of alternatives for improvement and optimisation. For this, a methodology has been designed that considers a global analysis of the thickening process, which starts from an experimental stage at a laboratory scale, then to a pilot-scale test stage, and finally a simulation of the process with computational tools. 


\section{Methodology}

The main goal is to attack the operational issues that arise in the thickener unit, by an analytical and experimental approach (Larenas et al. 2018; Larenas \& Garrido 2017). In order to do this, we fully characterised the variability of the tailings via certified tests such as sedimentation, rheology, granulometry, and pilot-scale thickening test. The focus considers the measurement of different operational variables of the thickening process in a semi-automatic way and that allows us to get the main parameters of the tailings as an input to the phenomenological model where we can design the optimal thickener or duplicate the behaviour of an existing unit. In our experience, when the parameters are tuned in, this model predicts the operational reality. Finally, with the data analytics, we can correlate the experimental characterisation with the operational reality, to do predictive analysis.

We can summarise this methodology by the schema in Figure 3.

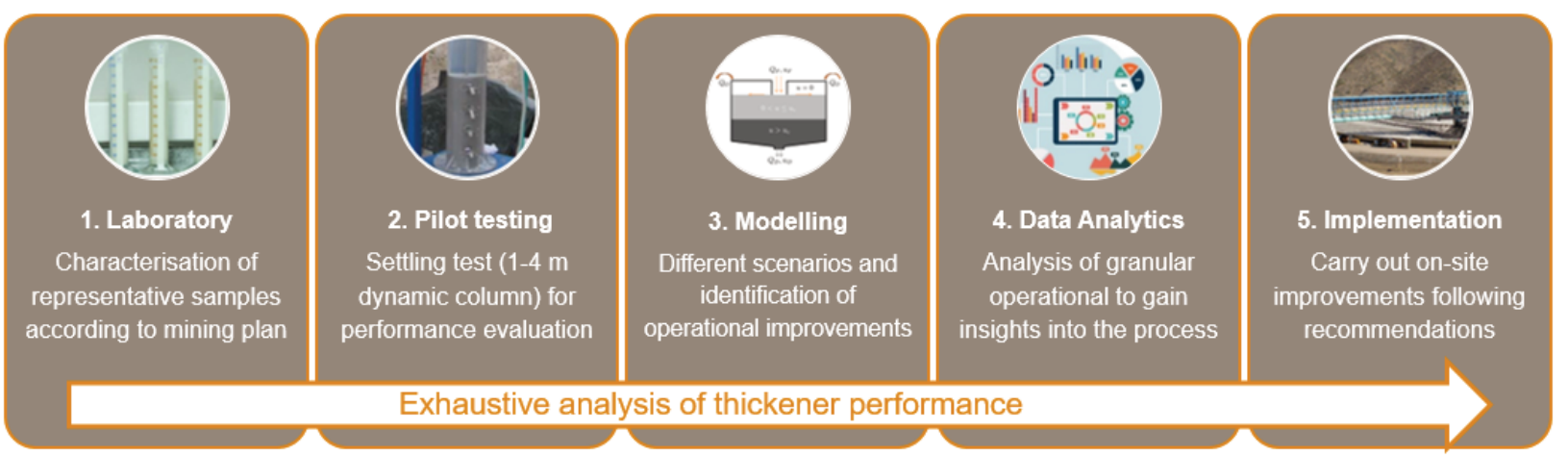

Figure 3 Comprehensive thickening analysis strategy Centro de Investigación en Minería Sustentable five-stage thickening analysis (STA-5S)

Due to changes in the mineralogy that is typical of any mining exploitation that generates variability in the behaviour of the tailings, this methodology must be complemented periodically (approximately once a year) with new information through short experimental campaigns, which will strengthen the predictive models already generated.

This analysis is a new way of evaluating the performance of the thickening unit since operational conditions can be replicated and projected in the device. The continuous study of the pulps that are treated in the operational life of the thickener allows us to improve the operation and planning by being able to test representative samples of the variability of the processes and simulate the responses of the thickener, and it will be possible to generate estimates of the future yields of the unit. The information generated can also be used for additional analyses such as the effect of mineralogy or variations in granulometry in the treatment and recovery of water (Garrido et al. 2013, 2016).

\section{$3 \quad$ Results}

An example of the implementation of this methodology is shown in the following subsection. It takes place in the mining site ' $X$ ', where the objective is to achieve the treatment tonnage of $55 \mathrm{ktpd}$ and a discharge concentration close to $60 \%$ solids.

\subsection{Laboratory characterisation}

After conducting the solid density, granulometry, rheology and sedimentation studies (Garrido et al. 2014), it was observed that the pulps from the mine can be classified into two large groups represented in Table 1. 
Table 1 Classification of mining pulps based on laboratory characterisation and characteristics of the thickeners studied at $\mathrm{Cp} 60 \%$

\begin{tabular}{lll}
\hline Type of pulp & Yield stress $\mathrm{Pa}$ & Sedimentation rate $\mathrm{m} / \mathrm{h}$ \\
\hline Complex samples & $>37.5$ & $<7$ \\
Less complex samples & $<37.5$ & $>7$ \\
\hline
\end{tabular}

We define complex samples as those that present unstable behaviour and poor operational response, since they mainly produce a considerable increase in torque, lower interface between solids and liquids, shallow depth of clear water from the surface, and high turbidity. With this, we can characterise the variability of the pulps that enter the thickener.

\subsection{Pilot-scale thickening tests}

The pilot-scale tests are carried out in similar conditions to those that occur in the plant (unit area, flocculant dosage, feed flow, etc.) and the results of these deliver final $\mathrm{Cp}$, turbidity at different times, and a general representation of the behaviour of the pulp entering the thickener (Garrido et al. 2013, 2016). With this information, it is possible to determine scale-up parameters, which will translate the results obtained in these experimental phases to the final model. The tests were carried out in two groups:

1. Standard tests: flocculant, flocculant dilution, and flocculant dose were kept constant.

All standard column tests are carried out under the same conditions (jointly defined between the mine and Centro de Investigación en Minería Sustentable [CIMS-JRI]), to evaluate the behaviour of the different samples and the operational response. Compared with rheological analyses obtained in the laboratory stage, it can be seen that the samples classified as complex in rheology (high yield stress values) present the lowest values of discharge concentration $\mathrm{Cp}$ (Figure 4).

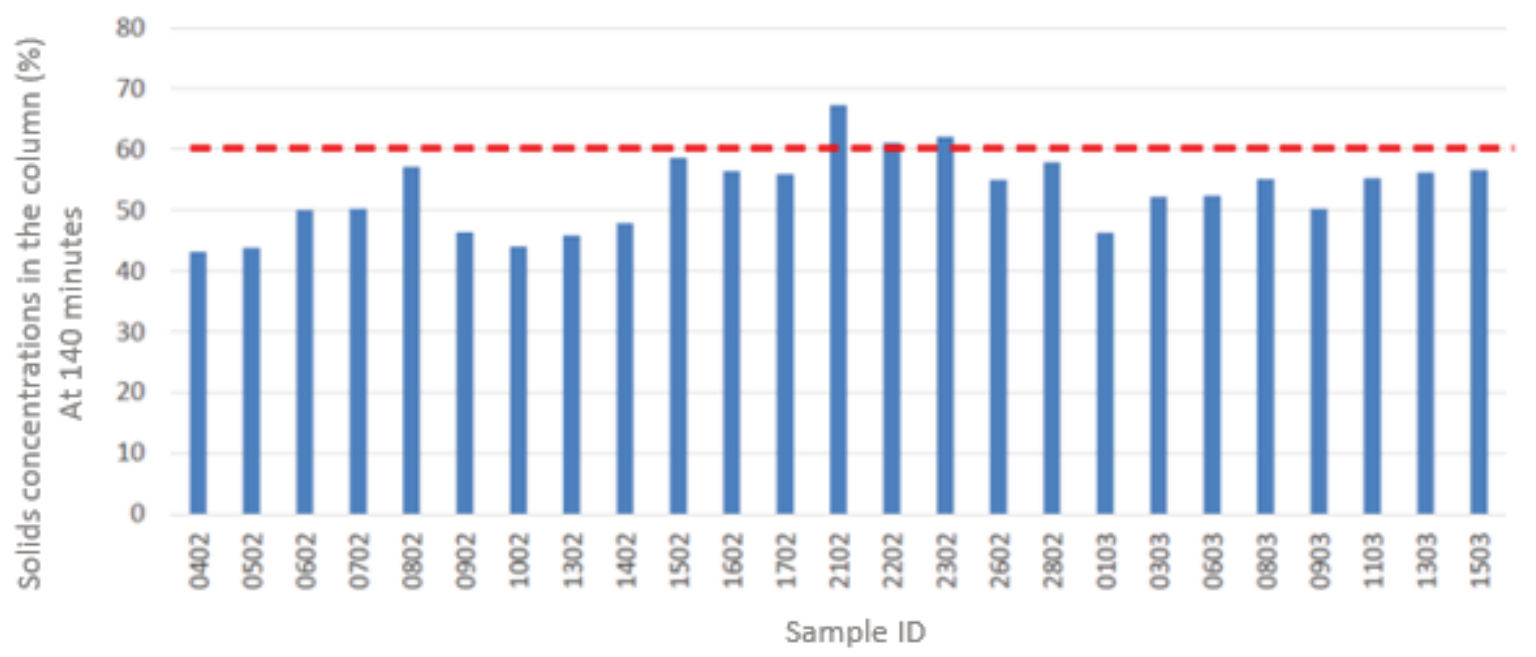

Figure 4 Cp of discharge after 140 min of test, for each sample studied

This can be corroborated by making the correlation between the yield stress of the samples and the discharge $\mathrm{Cp}$ presented in the pilot tests (Figure 5), in tests performed with different treatment rates (Au in $\mathrm{m}^{2} / \mathrm{tpd}$ ). 


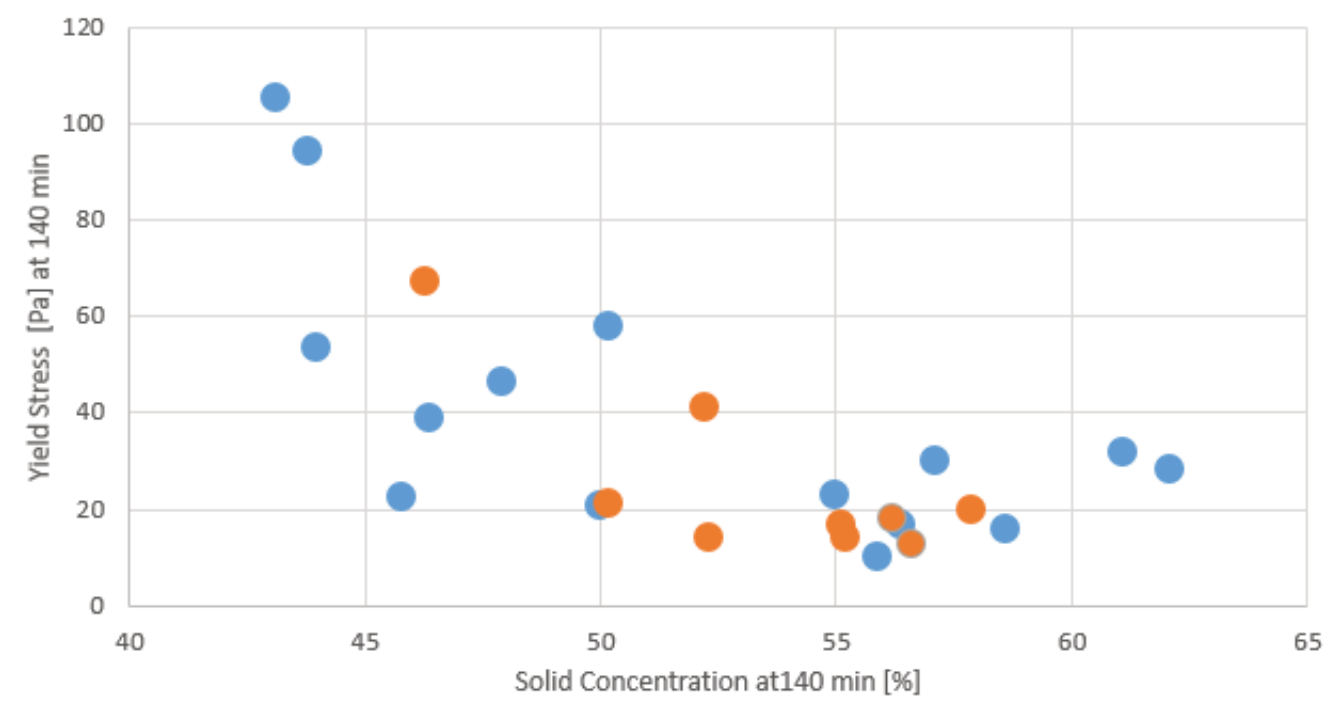

Figure 5 Yield stress measured at $\mathrm{Cp} 60 \%$ of the sample versus $\mathrm{Cp}$ thickening column discharge

An inverse correlation is observed such that the higher discharge $\mathrm{Cp}$ values are obtained at lower yield stress values. Operationally, in the samples in which the discharge $\mathrm{Cp}$ presents good yield stresses-that is, they will not produce typical problems in the thickener-the behaviour could be further improved, since a lower operating torque would be perceived.

2. Flocculant doses test: flocculant and flocculant dilution were kept constant. Two doses of flocculant were used in 8 and $12 \mathrm{~g} / \mathrm{t}$.

Table 2 shows that at a dose of $8 \mathrm{~g} / \mathrm{t}$, there is a decrease in discharge $\mathrm{Cp}$ and yield stress relative to $12 \mathrm{~g} / \mathrm{t}$. In addition, there is a substantial decrease in the height of clear water, which reaches values very close to zero and has a direct impact on the turbidity of the overflow, which reaches values greater than the measurement range of the method $(10,000)$.

Table 2 Classification of tailings based on laboratory characterisation

\begin{tabular}{lll}
\hline Parameter & $\mathbf{8 ~ g / t}$ & $\mathbf{1 2} \mathbf{~ g / t}$ \\
\hline Cp underflow (\%) & 38.7 & 42.5 \\
Yield stress (Pa) & 5.0 & 8.3 \\
Clear water height (cm) & 0.15 & 9.7 \\
Clear water turbidity (NTU) & $>10,000$ & 835 \\
\hline
\end{tabular}

\subsection{Mathematical modelling}

Once the pulp has been fully characterised, its variability identified, and the tests carried out in the semi-pilot column, the data is extrapolated using a mathematical model based on Bürger et al. (2005). This allows a 1:1 relationship to be obtained with the industrial thickener (Larenas 2016; Larenas \& Garrido 2017; Larenas et al. 2018). The type of thickener, its geometry, and feedwell design must be considered (Figure 6), and this data is digitised to calibrate the mathematical model. 


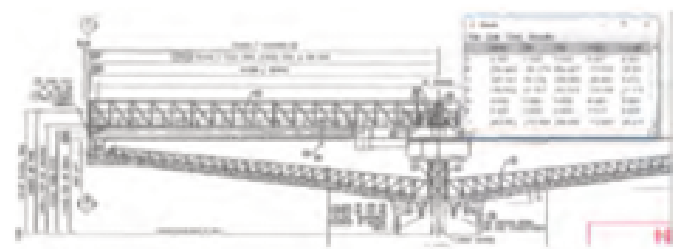

\section{Thickener planes}

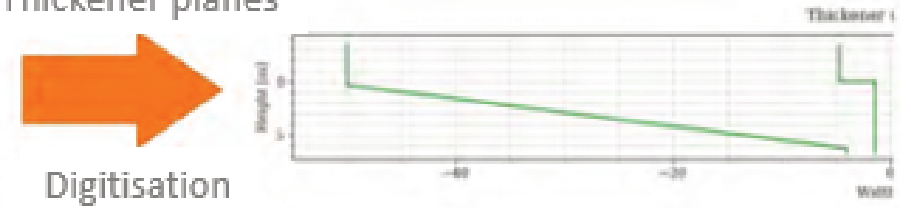

Figure 6 Digitisation of thickener planes for the configuration of the geometry

\subsection{Data analysis}

\subsubsection{Simulation of industrial thickeners}

The results presented below are simulations of a thickener under conditions of maximum flow, nominal flow, and operational flow of the day, for less complex slurries (Figure 7) and complex slurries (Figure 8).
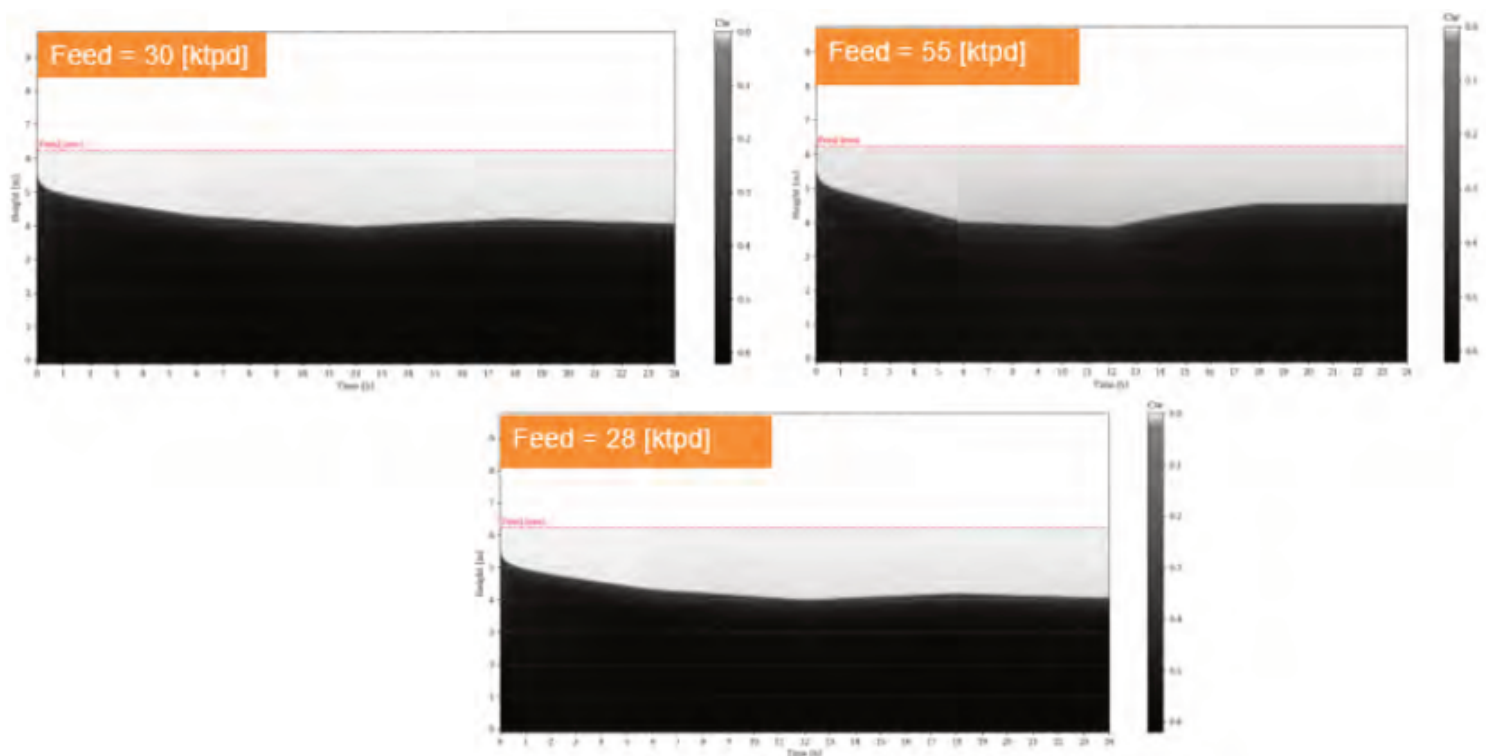

Figure 7 Simulation of a less complex case for nominal feed $30 \mathrm{ktpd}$, maximum feed $55 \mathrm{ktpd}$, and operational feed 28 ktpd

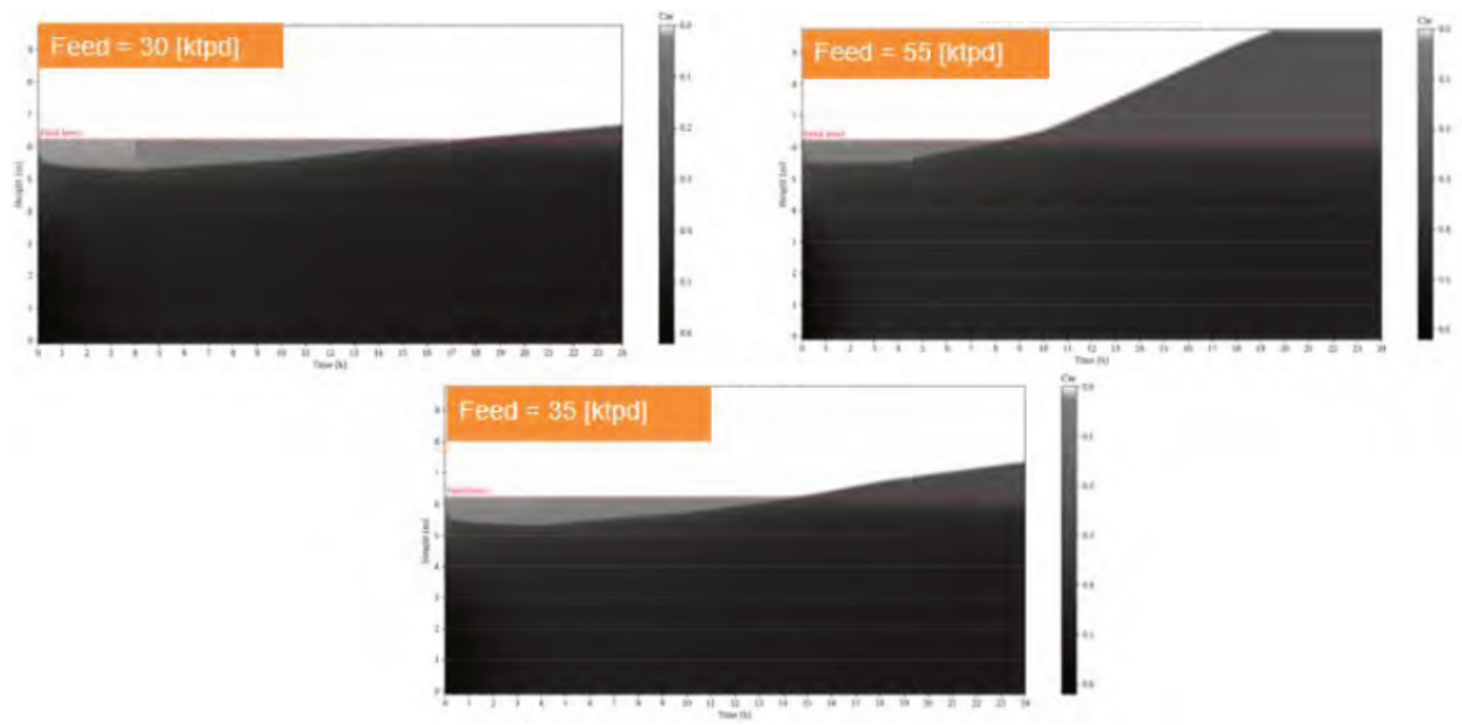

Figure 8 Complex case simulation for nominal feed 30 ktpd, maximum feed 55 ktpd, and operational feed 28 ktpd 
It is possible to observe that in the case of less complex pulps, the thickener can operate correctly with nominal and maximum load, however, for the complex case, we can see that in all simulated cases it is observed that the thickener loses all the clear water after 10 hours, creating operational difficulties (Figure 8).

\subsubsection{Analysis of simulation}

The greyscale in Figures 7 and 8 represents the concentration of solids within the thickener and this is defined as black for values close to $\mathrm{Cp} 65 \%$ and white for $\mathrm{Cp}$ values $0 \%$.

The results of the simulations of the less complex pulps (Figure 7) show us how the solid-water interface varies and the amount of clarified water that can be obtained in the thickener studied. In particular, for a feed of 30 and $28 \mathrm{kpd}$, the solid-water interface remains constant during the 24 hours of operation of the thickener and presents values close to $0.2 \%$ of solids concentration. In the case of feed at $55 \mathrm{ktpd}$, there is variability in the interface but this does not mean that the thickener can present bogging of discharge, as the clarified water amounts to $1 \%$. With these results and modifying the input parameters of the mathematical model, we can determine the ideal conditions to operate the thickener studied.

In the case of complex samples (Figure 8), it can be observed that the interface water sludge is initially unstable and that the clear water reaches $\mathrm{Cp} 10 \%$. After 10 hours of operation of the thickener, it presents issues of high clear water interface and this means that the thickener will collapse for more complex samples. Based on this, decisions can be made to avoid these problems, such as identifying complex pulps throughout the operational life of the thickener and distributing the pulp in two previously dimensioned thickeners.

\subsection{Implementation}

Complex pulps present operational difficulties that in extreme cases can leave equipment disabled for several days. The main restriction generated when processing this type of tailings is the maximum feed or treatment flow, which, in order to achieve relatively stable operating conditions, must be significantly reduced. On the other hand, when non-complex pulps are present, most operations perceive that everything is running according to plan, nevertheless it is possible to achieve better yields by stressing the operation obtaining more competitive metrics such as higher solid concentrations and more water recovery.

Through simulations and data analytics, it is possible to design an operational procedure that adapts the main goals of operation of a complex or non-complex scenario. In Figure 9, we observe that after the implementation of the identified operational improvements, thickener 1 and 2 gain operational stability, which in this case, are represented with a torque between $10 \%$ and $30 \%$.
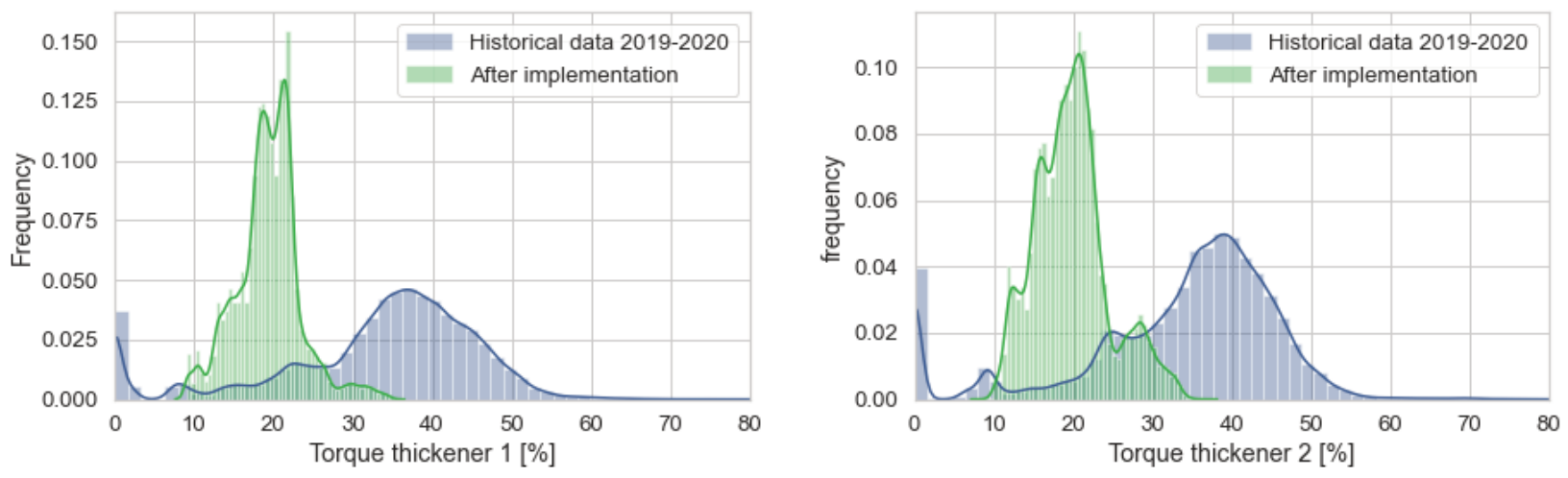

Figure 9 Two scenarios are presented: before the intervention (2019) and after the implementation of recommendations

The results of this integral study allowed generation of operational stability from the understanding of the variability of the tailings pulp during industrial operation. 


\section{Conclusion}

The comprehensive STA-5S, through the characterisation, complexity classification and pilot tests of a sample, allows us to understand the process and identify concrete actions to improve the thickening processes.

The results obtained in the simulations indicate that the scaling of the results of the pilot column to the industrial scale is satisfactory, confirming the good representativeness of the pilot test (column) and of the phenomenological model used. The information derived from the column tests allows the parameters of the simulations to be properly calibrated.

Finally, by being able to adjust the simulations, the treatment can be optimised considering when the samples are less or more complex in the mining plan, allowing the operator to make informed decisions that avoid bogging of the thickener, breakage of the rake arms due to high torque, underflow solid concentration, and high underflow yield stress.

\section{References}

Bürger, R, Karlsen, KH \& Tiwers, JD 2005, 'A model of continuous sedimentation of flocculated suspension in clarifier-thickener units', Society for Industrial and Applied Mathematics Journal on Applied Mathematics, vol. 65, no. 3, pp. 882-940.

Comisión Chilena del Cobre 2020, 'Proyección de consume de agua en la minería del cobre 2020-2030', (Forecast for water consumption in the copper mining industry 2020-2030), Dirección de Estudios y Políticas Públicas, Santiago.

Comisión Chilena del Cobre 2018, 'Proyección de consume de agua en la minería del cobre 2018-2019' (Forecast for water consumption in the copper mining industry 2018-2029), Dirección de Estudios y Políticas Públicas, Santiago.

Garrido, P, Aracena, I, Zandarín, M \& Rayo, J 2016, 'Geometallurgy of copper tailings applied to optimization of water recovery', Proceedings of the 3rd International Seminar on Tailings Geometallurgy, Gecamin, Santiago.

Garrido, P, Watt, T, Castillo, C \& Fuentes, R, 2014, 'Importance of fine material content in the rheological and thickening properties of Copper tailings', Proceedings of the 2nd International Seminar on Tailings Management, Gecamin, Santiago.

Garrido, P, Watt, T \& Rojas, N, 2013, 'Progress made in pilot and laboratory thickening study', Proceedings of the Copper International Conference, Instituto de Ingenieros de Minas de Chile, Santiago.

Larenas, M 2016, 'Implementación numérica y validación experimental de un modelo de espesamiento de suspensions floculadas' (Numerical implementation and experimental validation of a thickening model of flocculated suspensions), Congreso de Separación Sólido/Líquido y Tratamiento de Relaves (Proceedings of the 1st Solid/Liquid Separation and Tailings Treatment Congress), Santiago.

Larenas, M \& Garrido, P 2017, 'A model of solid-liquid separation of mining slurries: experimental validation and scale-up', Proceedings of the 4th International Seminar on Tailings Management, Gecamin, Santiago.

Larenas, M, Garrido, P \& Navarrete, J 2018, 'Characterization of industrial thickening through pilot-scale testing and numerical simulations', Proceedings of the 5th International Seminar on Tailings Management, Gecamin, Santiago. 